\title{
TEMPERATURE VARIATIONS IN INTERMITTENTLY- PUMPED WELLS WITHIN UNCONFINED ALLUVIAL AQUIFERS
}

Madan Maharjan

West Virginia University

Northern Illinois University (Current)

Joe Donovan

West Virginia University 


\section{BACKGROUND}
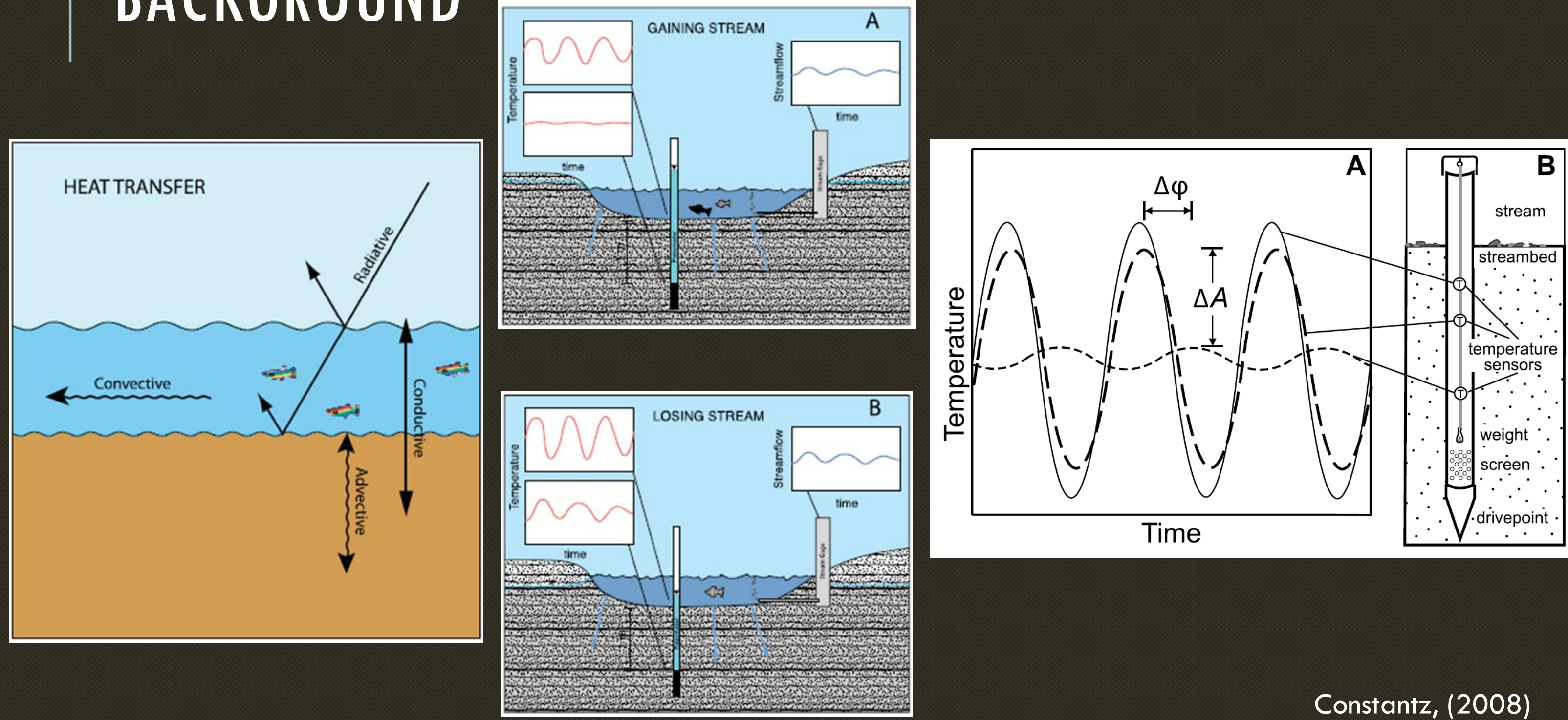

Constantz, (2008) 


\section{PURPOSE}

* To understand connectivity of groundwater and surface water near a leaky stream due to intermittent pumping

* To study feasibility of using heat as a tracer in bank storage zones 


\section{HYPOTHESIS}

* If pumping induces surface water, then the temperature of produced water differs from that of groundwater

\section{Approach}

* Recorded high-frequency temperature and water level from a stream and intermittently-pumped wells tapped into shallow unconfined aquifers near a leaky stream

* Lag time $(\tau)$ between groundwater and stream temperature was estimated by visual peak matching, with estimated uncertainty of \pm 5 days 


\section{STUDY AREAS}

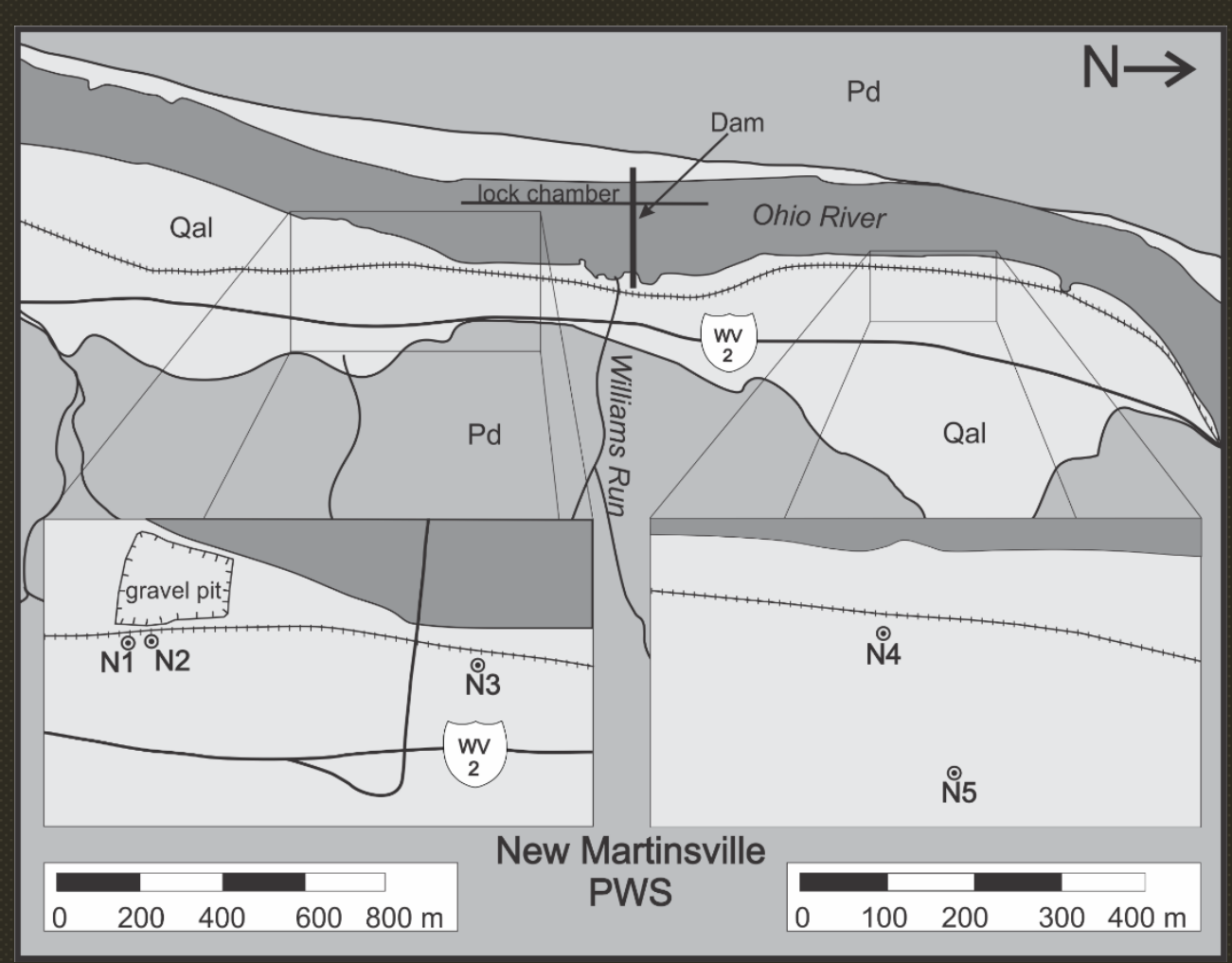

New Martinsville

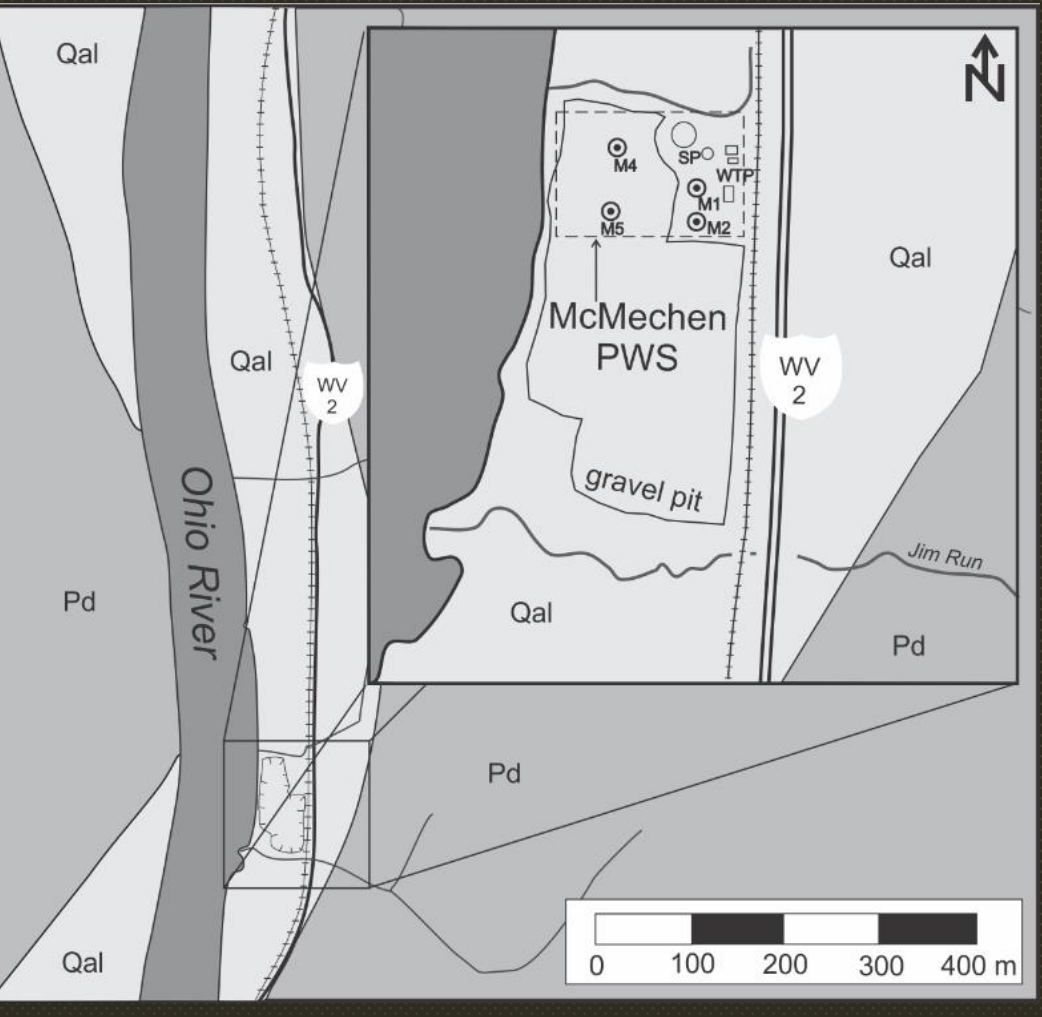

McMechen

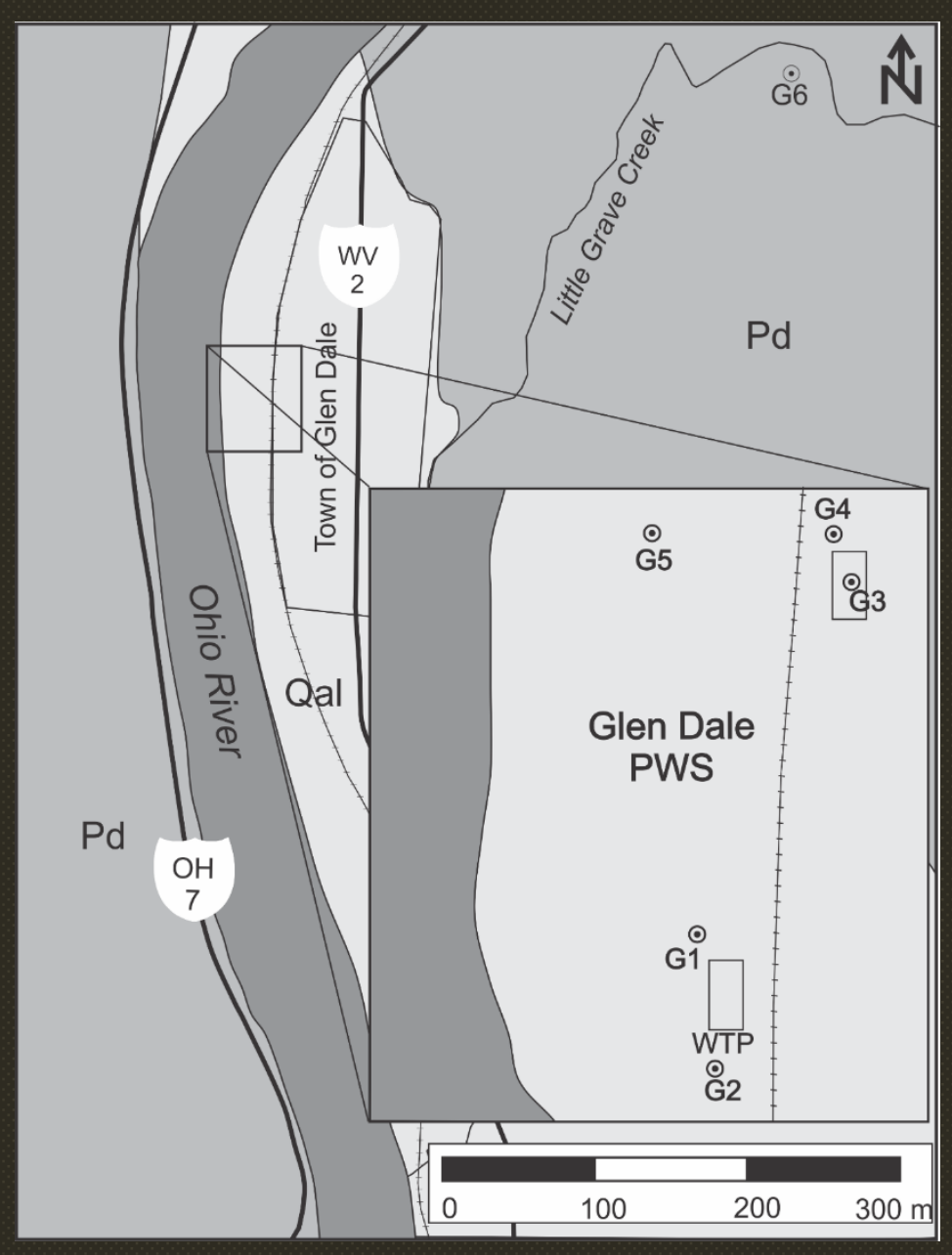

Glen Dale 


\section{CONCEPTUAL MODEL}

A conceptual geological crosssection of the Ohio River valley (top) with a pumping well and associated flow lines and (bottom) inferred heat transport mechanisms

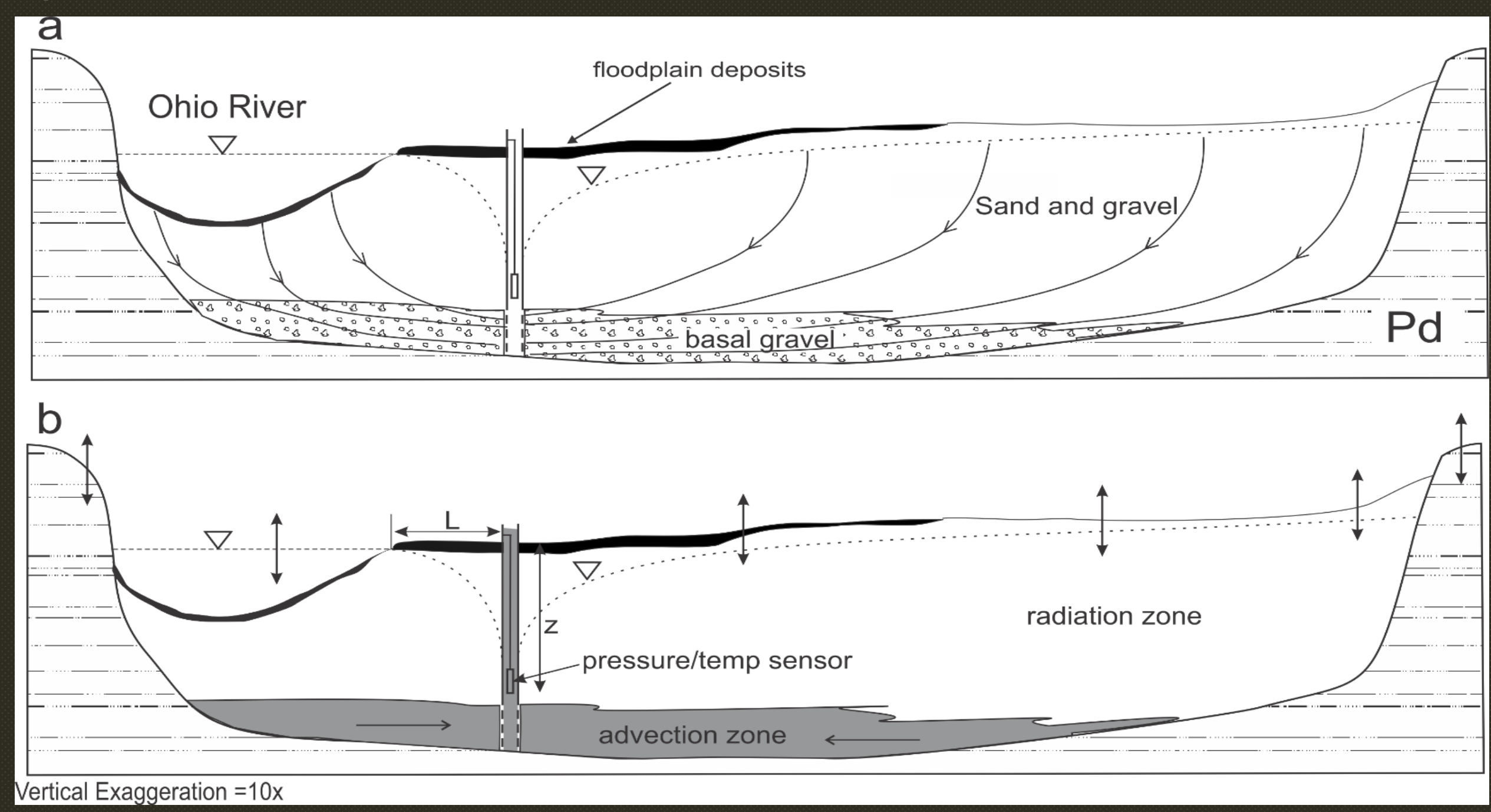




\section{ASSUMPTIONS}

* Fluid flow to the well is dominantly horizontal in the screened interval and dominantly vertical above it.

* Changes in subsurface temperature are slow and form nearly-horizontal isotherms in this radiation zone.

* In this horizontal flow zone, it is speculated that isotherms would be vertical. 
RESULTS

\section{Temperature} variations superimposed on seasonal fluctuations of water levels for well M5 between May 2014 and August 2016.

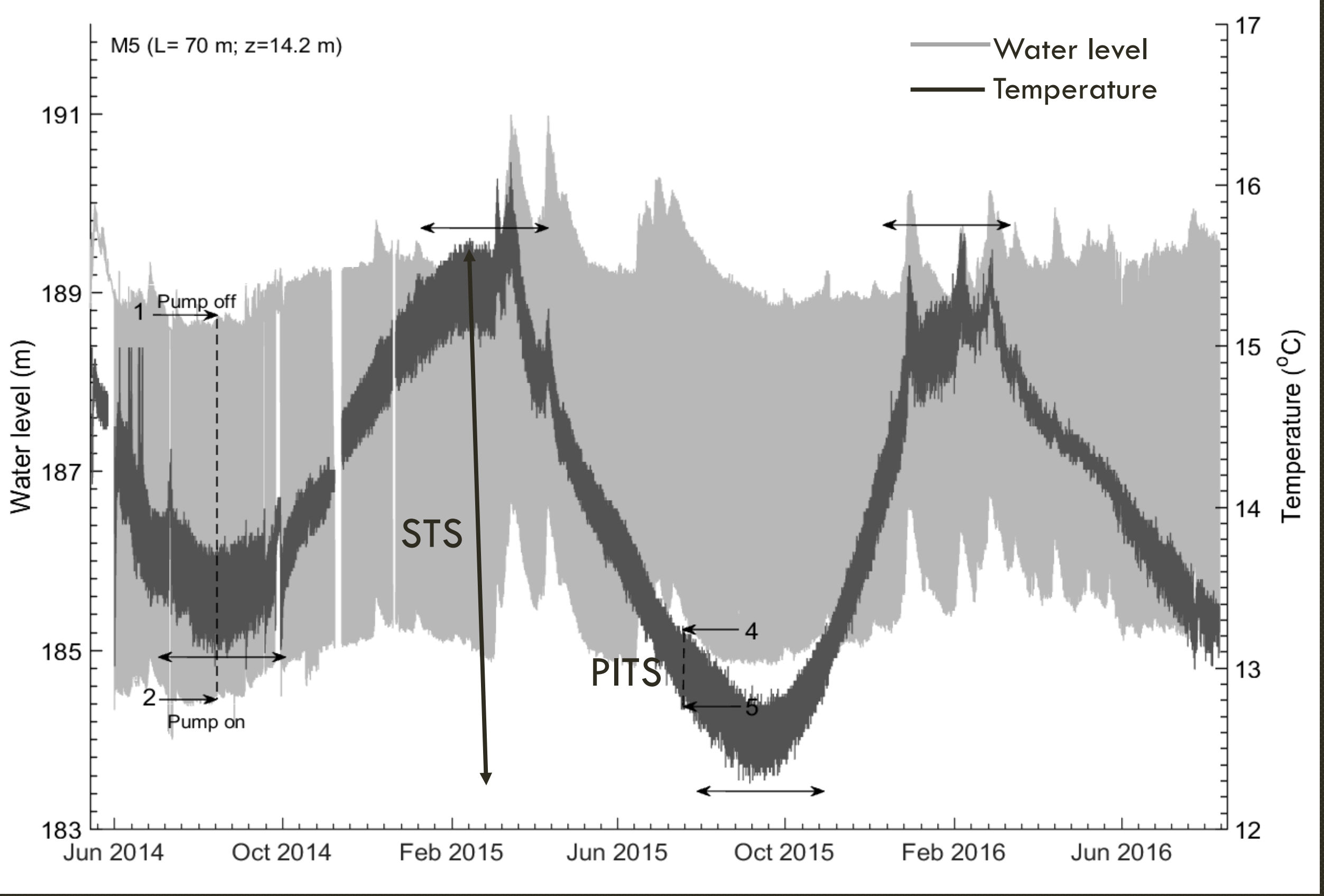




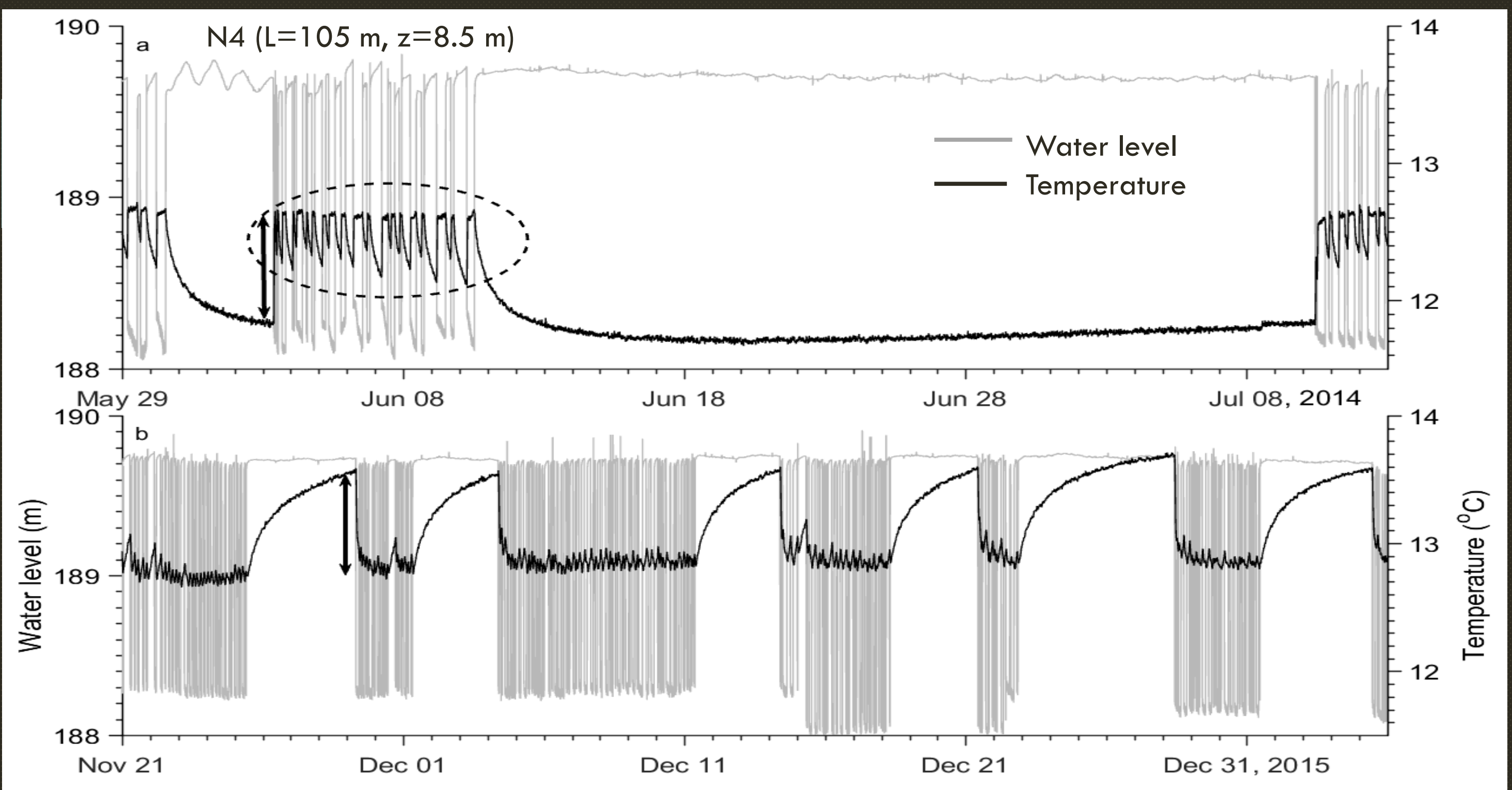

High-resolution PITS during different seasons for well N4. Each tick mark on the $X$-axes represents one day. 


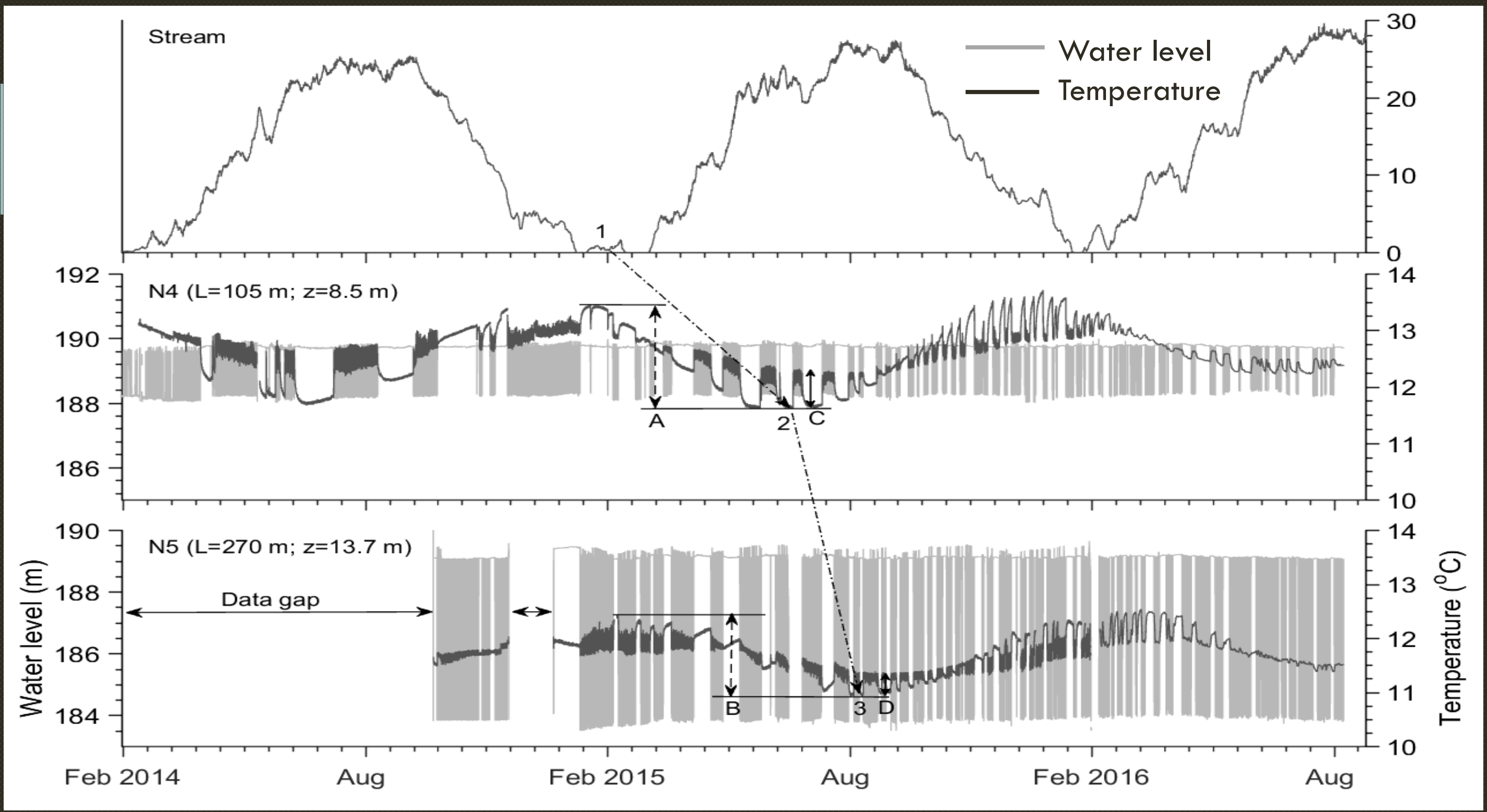

Stream temperature fluctuations (top), water-level, and temperature variations from February 2014 to August 2016 inside wells N4 and N5 


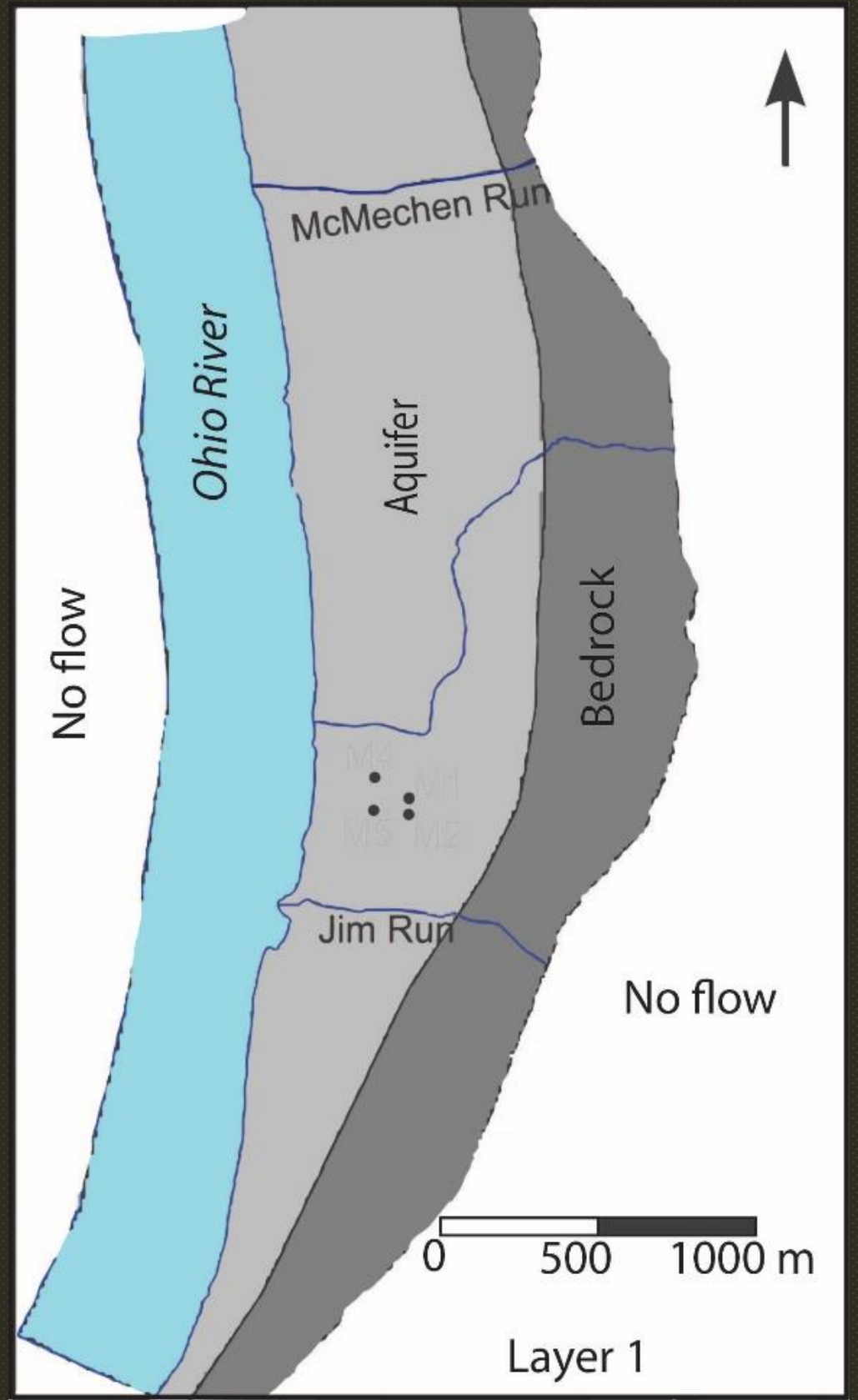

Model zonation
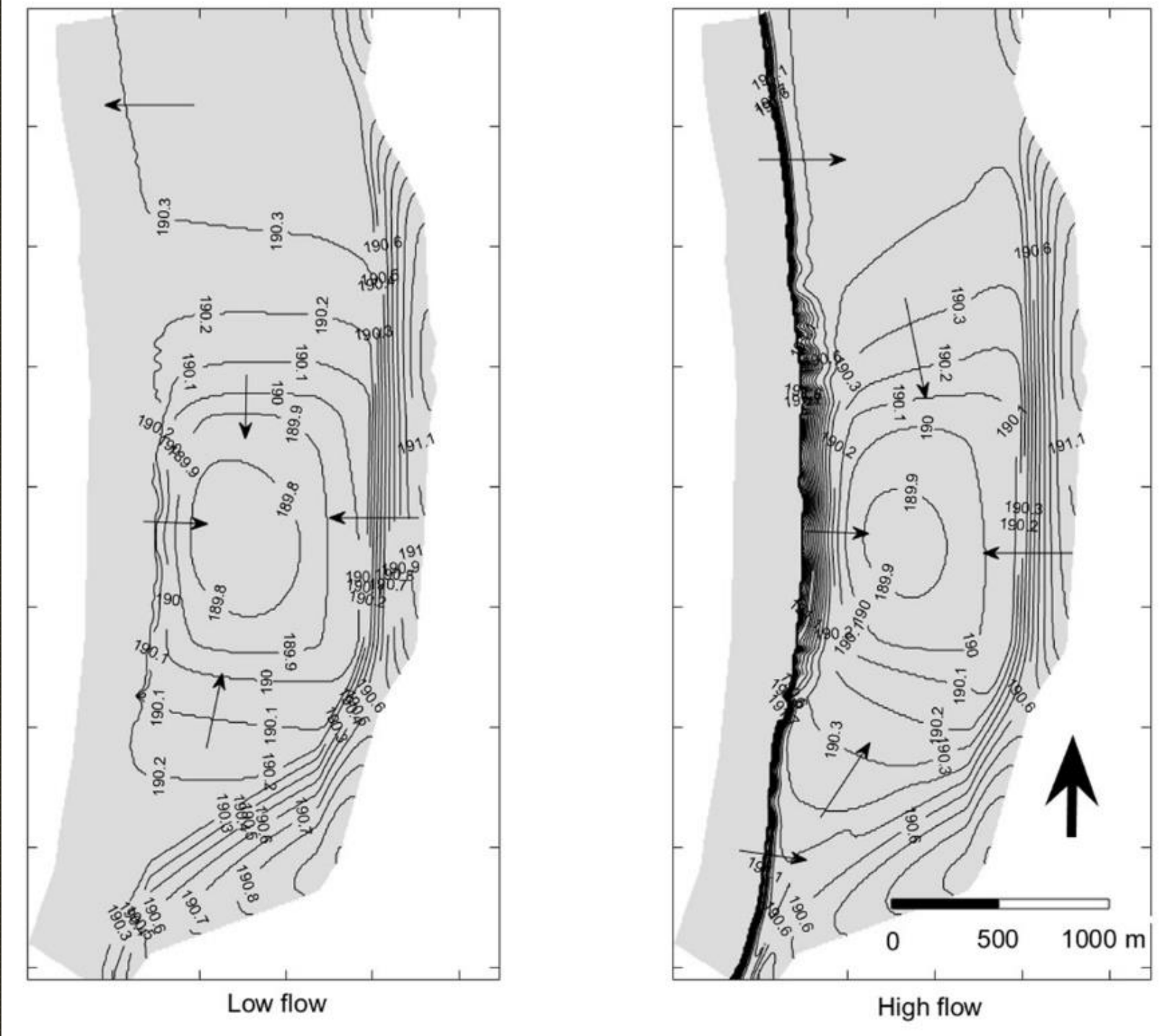

Head Distributions 


\section{LIMITATIONS}

* Results and interpretations are based on a limited number of observations

* Multiple sources of water could mix together obscuring temperature signals of the production water

* Different combinations of $L, z$, and pumping rate could substantially affect the magnitudes of PITS, STS, and lag time 


\section{CONCLUSION}

* Both water level and temperature in pumping wells change abruptly and continually in response to pumping.

* Water level and temperature changes (STS) were largest for wells closest to the surface and nearest to the river.

* The temperature difference between groundwater outside the casing and that produced by pumping (PITS) is highest during summer and winter

* Stream exfiltration occurs year round and constitutes a significant portion of the water budget for a number of wells.

* Water level and thermal data offer a reliable field-based method for observation of groundwater-surface water exchange in a bank storage zone. 


\section{ACKNOWLEDGEMENTS}

Funding agency: WVBPH

PWS Operators:

-Sean Orlofske ( Glen Dale)

- Gary William (McMechen)

-David Benson (New Martinsville)

Residence well owner:

-Dave Hall (Glen Dale) 


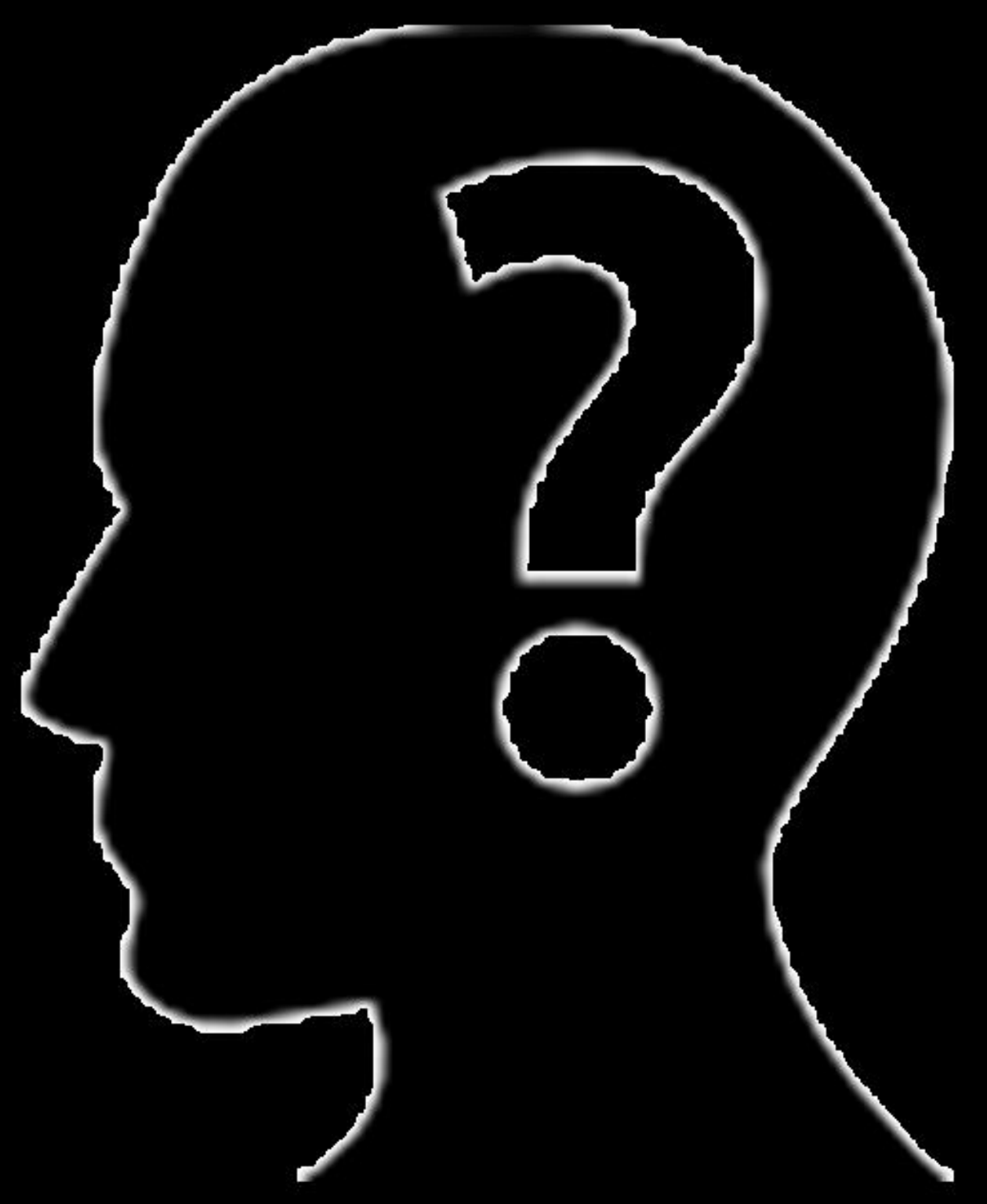

